\title{
Mediating Bullying and Strain in Higher Education Institutions: The Case of Pakistan
}

\author{
Ambreen Anjum ${ }^{1}$, Amina Muazzam 1,*(D), Farkhanda Manzoor ${ }^{2}$, Anna Visvizi ${ }^{3,4}{ }^{\mathbb{D}}$ and \\ Raheel Nawaz 5 (D) \\ 1 Department of Applied Psychology, Lahore College for Women University, Lahore, Punjab 54000, Pakistan; \\ ambreenaanjum@gmail.com \\ 2 Department of Zoology, Lahore College for Women University, Lahore, Punjab 54000, Pakistan; \\ drfarkhanda786@gmail.com \\ 3 School of Business \& Economics, Deree College-The American College of Greece, 153-42 Athens, Greece; \\ avisvizi@gmail.com \\ 4 Effat College of Business, Effat University, P.O. Box 34689, Jeddah 21478, Saudi Arabia \\ 5 Department of Operations, Technology, Events and Hospitality Management, Manchester Metropolitan \\ University, Manchester M1 5GF, UK; r.nawaz@mmu.ac.uk \\ * Correspondence: amina_muazzam@hotmail.com
}

Received: 11 March 2019; Accepted: 4 April 2019; Published: 15 April 2019

\begin{abstract}
Although workplace bullying is a well-researched phenomenon, the specific way it unfolds in higher education institutions (HEI) remains largely underdiscussed. Based on the outcomes of a survey conducted across HEI in Pakistan, by reference to structural equation modeling, using Amos-20, this paper not only adds to our understanding of the scope and features of bullying in HEI, but also suggests strategies employers and victims could employ to cope with the adverse implications of bullying. The key findings of this research are: (i) a positive correlation exists between the degree of workplace bullying and strain levels; (ii) more frequently than not, female employees, younger employees, and employees in junior positions are victims of bullying; (iii) bullying and strain can be fully mediated only when both emotion-focused and problem-focused coping strategies are employed in synergy. In brief, although research findings elaborated in this paper draw from the specific case of HEI in Pakistan, this paper makes a case for more research, vigilance and action to understand the scale of the phenomenon in academia and to undertake concerted action to mitigate its adverse impact on specific individuals and HEI themselves.
\end{abstract}

Keywords: workplace bullying; HEI; coping strategies; administration; sustainability

\section{Introduction: Understanding the Specificity of Bullying in HEI}

Workplace bullying is the systematic, repetitive, and intended undesirable behavior of one employee or group of employees directed at another employee or group of employees. Such behavior might consist of public humiliation and condemnation, social segregation, verbal exploitation, intimidation, inaccurate allegations, ignoring someone for a long period of time, and repeated reminders of someone's errors [1]. Workplace bullying is also referred to as abuse in the workplace, mobbing, harassment, and mistreatment [2-4]. Often, bullying is a reflection of a systemic malfunction of a given institution rather than of direct personal animosities. Considering the spread of the phenomenon and the adverse effects it generates for both victim employees and the employer, research on workplace bullying thrives [5-7].

In the debate on workplace bullying, higher education institutions (HEI), unfortunately, do not constitute an exception. Bullying in HEI is common, even if it is rarely discussed openly. This notwithstanding, academic research on bullying in HEI is still nascent. Today, perhaps as never before, 
HEI are exposed to a variety of challenges, including issues of financing, curriculum development, student retention, work load management, and talent management [8]. The degree of strain that is thus created in HEI institutions is immense. In this context, bullying in HEI constitutes a yet another challenge that effectively undermines the efficiency and sustainability of HEI. Several interconnected layers of the problem can be identified; these include the implications for the individuals affected, for students, for the organizational culture, and as a result, for the entire institution as well as for the process of teaching and learning. Taken together, these implications, some of which are further explored in this paper, prompt very serious questions directly related to the broader debate on smart sustainable education [9].

Given the perceived scope and scale of the phenomenon in HEI, and its relative absence from academic research, the objective of this paper is to make a case for the need of a thorough, systematic study of bullying in HEI. This paper draws from the outcomes of a survey conducted across HEI in Pakistan. It employs structural equation modeling, Amos-20, to examine the mediating role of coping strategies (both emotion-focused and problem-focused strategies) on the relationship between workplace bullying and bullying strain. Even if this paper employs the case of Pakistan, clearly the problem is endemic to HEI worldwide. In this view, more effort is needed to examine, understand and prevent bullying in HEI $[3,5,6]$. The reminder of this paper is structured as follows. Following the literature review, the methodological framework and key findings of the research are outlined. In the next step, the latter are discussed in detail. Conclusions follow.

\section{Literature Review}

To prevent workplace bullying, it is important to understand the setting in which it takes place. The typical HEI environment is intrinsically susceptible to bullying. Particularly, hierarchical structure, faculty evaluations based on subjective performance measures, and the (sometimes) competing goals of teachers and administrators are the chief reasons for the increased prevalence of bullying in HEI than other organizations. For example, a large-scale study conducted on 779 educators revealed that 46.5 percent had been subjected to bullying [10]. HEI possess an atypical environment; partly because most HEI managers and senior administrators come from an academic background and have little or no formal training or education in effective management styles. Owing to these distinctive characteristics, it is vital to explore how employees interact in such settings, with peers, superiors and subordinates. Furthermore, some employees face more bullying than others. Studies conducted on gender issues report that female employees had more exposure to bullying [2-8]. Previous studies have shown that young employees, and employees with less experience and a relatively lower level of education, also had more exposure to bullying in higher education institutes [8-10]. Previous studies have identified that higher education institutions present a higher risk of workplace bullying. Furthermore, it has been argued that university administrators and heads of faculty are hesitant to admit that there is any form of bullying in their institution because it may perceive to be a result of their own poor management or leadership [11]. Though the contributing specific factors have not been thoroughly investigated, it can be concluded that bullying in HEI has become a problem that is too costly to ignore.

The direct cost of bullying is brain drain, which is a serious loss of economy to any developing country. Brain drain is becoming a serious issue for Pakistan. It is reported that in 2013, 2.7 million Pakistanis left the country in the preceding five years to find better work opportunities because of lack of resources and positive organizational culture which is free of bullying and harassment [12]. This is an alarming condition as Pakistan is losing its human capital rapidly which directly impacts the development of our economy. Furthermore, Pakistan's higher education sector is challenged because of serious budget cuts in the past three years. Consider that the budget for all universities of Pakistan has been cut down by more than 60 percent over the past three years [13]; with such limited resources, HEI cannot afford failing productivity related to employees' disengagement and turnover.

A British survey involving 5000 employees also reported that over one million workdays were lost because 1 in 10 employees had stress stemming from bullying [14]. Supporting the point regarding cost, 
Namie and Namie [15] reported that bullying cost American institutions close to US\$64 billion annually due to employee disengagement and turnover. However, no such statistics are available for Pakistan. The importance of studying the phenomenon of bullying is demonstrated by its severe negative effects on teachers' psychological and physical health. The victims of bullying experience physical ailment (e.g., heart disease, sleep problems, headaches), psychological problems (e.g., depression, anxiety), and behavioral strain (e.g., aggressive behavior, sudden crying) [10,11]. Bullied employees are more likely to have poor relations with co-workers and even the family members. Such serious individual consequences, in turn, lead to severe institutional outcomes, as bullied employees experience a low level of job satisfaction and are much more likely to leave the institution. Furthermore, when an institution has the reputation of being a hostile work environment, recruitment can be challenging, which can cause skills deficiency [11].

Coping is the constant cognitive and behavioral effort to deal with particular straining, stressful, and overbearing internal and/or external demands. Coping with workplace bullying consists of the victim's emotional and behavioral efforts to reduce or master the demands created by an extremely stressful bullying situation [3,16-18]. Researchers have studied coping, particularly in relation to exposure to bullying, and describe two main types of coping, namely problem-focused coping and emotion-focused coping [19]. Problem-focused strategies are employed to alter the source of stress. Carver [20] identified planning and taking active action as problem-focused coping strategies. Emotion-focused strategies are employed to reduce the emotional distress associated with the stressful situations [20]. Talking with friends and seeking emotional support are examples of emotion-focused coping. Emotion-focused strategies use an individual's cognitive abilities to arrive at a solution that might not be achievable when they are feeling overwhelmed.

Despite widespread recognition of the issue, workplace bullying in HEI largely remains an under-studied area of research. In the context of Pakistan, in recent years the prevalence of workplace bullying has generally risen [21]. The scarcity of studies on this issue and the deleterious effects are the motivation for this study. Another strong rationale for conducting the research is the fact that demographic variables such as age, education, marital status, and particularly gender are significant. However, the association between bullying and demographic variables remains largely unexplored, especially in the context of HEI in the developing world. Furthermore, workplace bullying in HEI is a serious phenomenon, yet the management strategies adopted and adapted by the bullied faculty members have not been thoroughly investigated [22]. Therefore, the objectives of this study were threefold: (i) to explore the scale of the phenomenon of bullying in HEI in Pakistan, (ii) to identify which groups are more vulnerable to bullying in HEI; (iii) to establish what types of coping strategies victims can employ to counter bullying most efficiently.

\section{Methodological Framework}

\subsection{The Sample}

A sample of 400 faculty members $($ men $=200$, women $=200)$ was selected from seven large public sector universities of Punjab, one of the highly populous provinces of Pakistan. The sample was selected using convenience sampling because workplace bullying is a very sensitive issue and a random sampling was difficult. The age of participants was from 23 to 60 years $(\mathrm{M}=33.40, \mathrm{SD}=8.0)$. It was ensured carefully that the sample will include young as well as experiences teachers. Most of the participants were married (75\%). The base line of academic qualification of the sample was sixteen years of education. 20\% participants held master's degree, $65 \%$ held MS/M.Phil degrees, whereas 15\% participants were Ph.Ds. 55\% of participants had more than five years of teaching experience. Only those university teachers who had at least one year of work experience were included. The sample selection was challenging yet provided us an authentic pool of representative sample for the study. 


\subsection{Measures}

\subsubsection{Workplace Bullying Scale (WBS)}

Participants' exposure to bullying was assessed on the workplace bullying scale (WBS). This scale was developed in the cultural context of Pakistan [23]. It consists of 21 items. All items are written in a behavioral form, and none specifically uses the word "bullying". Sample items include spreading rumors about someone's private life, persistent criticism, withholding necessary information that may affect someone's professional life, and so on. Cronbach's alpha of Workplace Bullying Scale 0.87 [24], 0.87 , and 0.77 , for Person-related bullying, and work-related bullying respectively indicate that WBS is internally consistent. Scoring was on a five-point Likert rating scale, where 'Never' scored 1 and 'Daily' scored 5.

\subsubsection{COPE Inventory}

The COPE Inventory was developed to assess the coping strategies employed in the event of exposure to bullying [25]. The inventory consists of 28 items and features two types of coping strategies: problem-focused coping strategies (comprising 10 items, e.g., taking action to make the situation better, seeking advice or help from other people about what to do); and emotion-focused coping strategies (comprising 11 items, e.g., acceptance of problem, seeking social support). The Cope Inventory is scored on a four-point rating scale ranging from 1, "I usually don't do this", to 4, "I do this a lot". Cronbach's alpha achieved in this study is 0.86 and 0.79 , respectively, for problem-focused and emotion-focused coping strategies. A higher score indicates a more rigorous use of coping strategies.

\subsubsection{Workplace Bullying Strain Scale (WBSS)}

To assess bullying strain, the Workplace Bullying Strain Scale (WBSS) was used [25]. It consists of 33 items. Sample items are "I feel a lack of interest in my office work", "These days I feel depressed about the problems in my job", and "I have trouble falling and staying asleep". It is on a five-point scale ranging from 1, "Never", to 5, "Always". Respondents scoring highly on the WBSS show a greater bullying strain. Cronbach's alpha acquired from this data is 0.90 .

\subsubsection{Procedure}

After obtaining written permission from the universities' management, the researchers contacted the teachers individually. Only those employees who agreed formally to take part in the research were included. Written Informed consent was taken. All participants were informed about the nature and aim of the study. Written guidelines were individually provided on filling out the questionnaires: a demographic information form; the WBS questionnaire; the WBSS questionnaire; and a coping questionnaire. Initially, 521 university teachers were invited, and 400 teachers returned the completed questionnaires. All participants were assured that the information provided by them would be kept confidential.

\section{Key Findings}

Descriptive statistical means and standard deviations of the demographic variables were described. To assess the internal consistency of the questionnaires, reliability analyses were run and Cronbach's alphas of all scales and subscales were obtained. Pearson's correlation analysis was conducted to assess the associations among the study variables. Mediation analysis was run to identify the relationship between bullying and strain in the presence of coping [26,27]. T-test and analysis of variance (ANOVA) were used to assess group differences that related to demographic variables. Cohen's $d$ was calculated as an effect size for $t$-tests [28].

Table 1 showed the alpha coefficient of all scales used in this study is satisfactory indicating all measures are internally consistent. Furthermore, all study variables have relationship in the proposed 
direction. Bullying is positively correlated with strain and problem-focused and emotion-focused coping, while coping is negatively correlated with strain.

Table 1. Means, standard deviations, Cronbach's alpha, and Pearson correlations of variables.

\begin{tabular}{ccccc}
\hline Variables & $\mathbf{1}$ & $\mathbf{2}$ & $\mathbf{3}$ & $\mathbf{4}$ \\
\hline 1. Bullying & - & - & - & - \\
2. Problem-focused coping & $0.40^{* *}$ & - & - & - \\
3. Emotion-focused coping & $0.44^{* *}$ & $0.88^{* *}$ & - & - \\
4. Strain & $0.25^{* *}$ & $-0.14^{* *}$ & $-0.21^{* *}$ & - \\
Mean and SD & $53.84 \pm 10.63$ & $23.72 \pm 10.26$ & $22.60 \pm 10.11$ & $92.14 \pm 25.75$ \\
Cronbach's alpha & 0.87 & 0.86 & 0.79 & 0.84 \\
\hline
\end{tabular}

The results (see Table 2$)$ showed that female employees $(\mathrm{M}=58.79, \mathrm{SD}=10.88),(t(398)=-10.50$, $p<0.000), \mathrm{d}=1.05$, and unmarried employees $(\mathrm{M}=51.30, \mathrm{SD}=12.48),(t(398)=-14.53, p<0.000)$, $\mathrm{d}=1.70$ were more bullied. Employees working on a contract basis $(\mathrm{M}=51.30, \mathrm{SD}=12.48)$, $(t(398)=-15.93, p<0.000), \mathrm{d}=2.12$ and with less work experience $(\mathrm{M}=51.30, \mathrm{SD}=12.48)$, $(t(398)=-8.72, p<0.000), d=0.83$ also had more exposure to workplace bullying.

Table 2. Demographic characteristics of sample by workplace bullying.

\begin{tabular}{ccccc}
\hline Variables & $\mathbf{M ~ ( S D )}$ & $\mathbf{t}$ (398) & $\boldsymbol{P}$ & Cohen's d \\
\hline Gender & & & & \\
$\quad$ Male & $48.90(7.67)$ & -10.50 & 0.001 & 1.05 \\
$\quad \begin{array}{l}\text { Female } \\
\text { Marital status } \\
\quad \text { Married }\end{array}$ & $58.79(10.88)$ & & & \\
$\quad$ Unmarried & $64.1(8.74)$ & -14.53 & 0.001 & 1.70 \\
Nature of job & & & & \\
$\quad \begin{array}{l}\text { Permanent } \\
\text { Contract }\end{array}$ & $50.30(8.63)$ & -15.93 & 0.001 & 2.12 \\
Work experience & $67.10(6.86)$ & & & \\
$\quad>5$ years & $50.30(12.48)$ & -8.72 & 0.001 & 0.83 \\
$\quad<5$ years & $59.02(8.02)$ & & & \\
\hline
\end{tabular}

The results (see Table 3 ) showed a significant difference between the groups on the basis of age and WBSS rank: younger employees $\mathrm{F}(3,396)=73.10, p=0.000, \eta^{2}=0.21$ and employees on lower grades were more bullied $\mathrm{F}(3,396)=72.09, p=0.000, \eta^{2}=0.35$.

Table 3. Analysis of variance to compare teachers' scores on bullying scale by age and rank $(\mathrm{N}=400)$.

\begin{tabular}{clcccccc}
\hline Variable & $\begin{array}{c}\text { Source of } \\
\text { Variance }\end{array}$ & Df & SS & MS & F & $\boldsymbol{P}$ & $\mathfrak{\eta}^{2}$ \\
\hline Age & Between-group & 3 & 9627.57 & 5379.99 & & & \\
& Within-group & 396 & $35,460.12$ & 73.10 & 73.59 & 0.000 & 0.21 \\
& $\quad$ Total & 399 & $45,087.69$ & & & & \\
\hline \multirow{2}{*}{ Rank } & Between-group & 3 & $16,139.98$ & 5379.99 & & & \\
& Within-group & 396 & $28,947.71$ & 72.09 & 73.59 & 0.000 & 0.35 \\
& Total & 399 & $45,087.69$ & & & & \\
\hline
\end{tabular}

\section{Mediation Analysis}

Analysis by structural equation modeling, using Amos-20, was conducted to assess the mediating role of coping strategies (both emotion-focused and problem-focused strategies, see Figure 1) on the 
relationship between workplace bullying and bullying strain. Table 4 presents the preliminary model fit of the estimates.

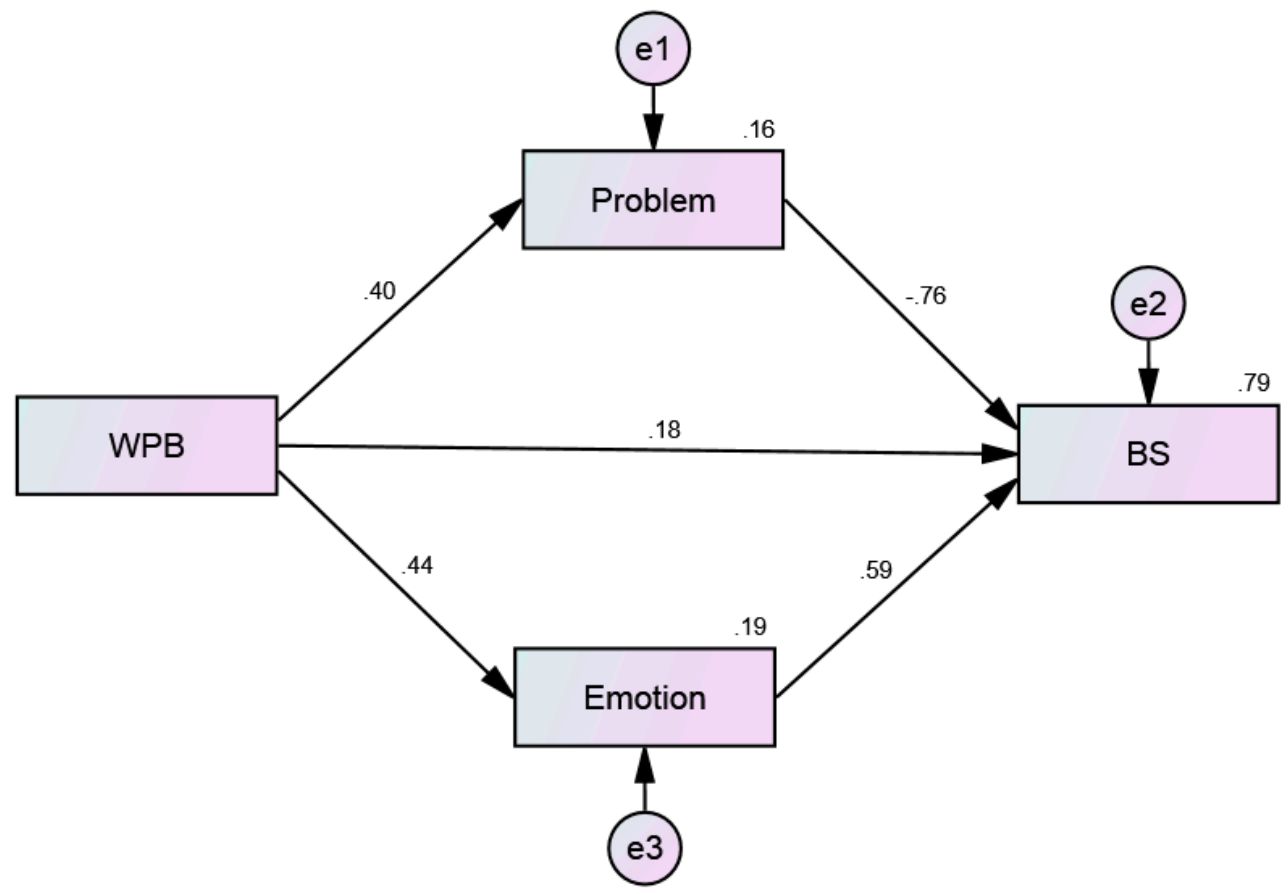

Figure 1. Preliminary model to assess the mediating role of emotion-focused and problem-focused coping on the relationship between workplace bullying and bullying strain.

Table 4. Fit indices for exposure to bullying, problem-focused and emotion-focused coping, and bullying strain $(\mathrm{N}=400)$.

\begin{tabular}{ccccccccc}
\hline Model & $\mathbf{X}^{\mathbf{2}}$ & $\mathbf{D f}$ & $\boldsymbol{\chi}^{2} / \boldsymbol{d f}$ & CFI & GFI & NNFI & RMSEA & SRMR \\
\hline Initial M & 108.00 & 1 & 108.100 & 0.91 & 0.86 & 0.75 & 0.09 & 0.08 \\
Final M & 0.07 & 1 & 0.07 & 99 & 1 & 0.97 & 0.03 & 0.05 \\
\hline
\end{tabular}

Initial $\mathrm{M}=$ initial model, Final $\mathrm{M}=$ final model, $\chi^{2}=$ hi square change, $\mathrm{DF}=$ degree of freedom, $\mathrm{CFI}=$ comparative fit index, GFI = goodness of fit index, NNFI = non-normed fit index, RMSEA = root mean square error of approximation, SRMR = standardized root mean square

Table 4 shows the results of the fit indices for exposure to workplace bullying, problem-focused and emotion-focused coping, and bullying strain. The absolute fit for the model was $\chi^{2} / d f=0.07$ $p<0.001$. The fit indices were considered to provide an indication of a good fit of the data to the tested model.

To test the model, our criterion for a good fit to the data was the fit indices. We examined the model fit in a single, key step, comparing the indices of relative and absolute fit (GFI $>0.90$, CFI $>0.90$, NNFI $>0.90$, RMSEA $<0.05$, and SRMR $<0.08$ ). Because chi-square is extremely sensitive to sample size, researchers use numerous fit indices to assess a model. The results from our preliminary model (Table 4) showed that it did not offer a good fit to the data, according to the fit indices suggested by Bentler [27]. So, modifications were made (see Figure 2). The modified indices proposed covariance between the error terms of the problem-focused and emotion-focused coping strategies. Covariance between both types of coping was drawn on a theoretical basis, as well. 


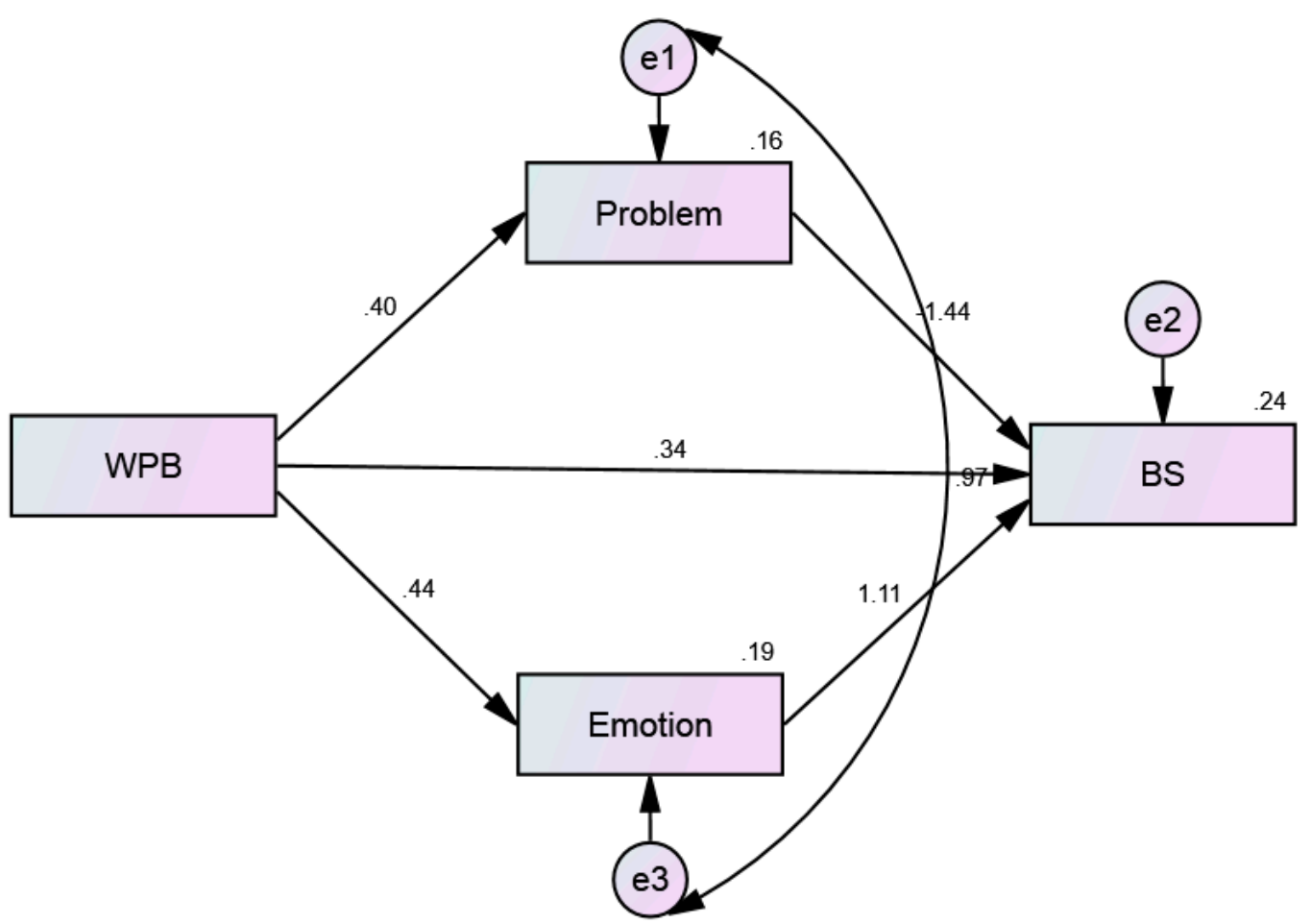

Figure 2. Revised model for the mediating role of emotion-focused and problem-focused coping on the relationship between workplace bullying and bullying strain.

Applying Arbuckle's criteria [29], covariance was drawn only when the chi-square change was 4 or larger. On this second attempt, the indices of relative and absolute fit (GFI, CFI, NNFI, and RMSEA) matched, and were good enough to fit the data (Table 4 and Figure 2). Furthermore, the direct and indirect effects of exposure to workplace bullying, problem-focused and emotion-focused coping, and bullying strain in a 5000-strong bootstrapped sample of university teachers were examined [30,31] (see Table 5 and Figure 2).

Table 5. Standardized direct, indirect, and total effects of workplace bullying on bullying strain $(\mathrm{N}=400)$.

\begin{tabular}{cccccc}
\hline Predictor & Outcome & Direct Effect & Indirect Effect & Total & $\boldsymbol{P}$ \\
\hline Bullying & Strain & 0.34 & -0.09 & 0.25 & 0.211 \\
Bullying & Problem-focused coping & 0.40 & 0.00 & 0.20 & 0.001 \\
Bullying & Emotion-focused coping & 0.43 & 0.00 & 0.35 & 0.001 \\
Problem-focused coping & Strain & 1.44 & 0.00 & 1.43 & 0.001 \\
Emotion-focused coping & Strain & 1.11 & 0.00 & 1.11 \\
\hline
\end{tabular}

The results of the indirect effects (mediated) showed that problem-focused and emotion-focused coping strategies acted as significant mediators on the relationship between workplace bullying and bullying strain.

\section{Discussion}

Our study revealed a significant positive correlation between workplace bullying and bullying strain, meaning that employees who experienced more bullying reported an increased level of strain. Our findings are in accord with previous research [32]. Furthermore, workplace bullying is significantly and positively correlated with problem-focused and emotion-focused coping. Problem-focused and emotion-focused strategies are negatively correlated with bullying strain, meaning that the more that they are used by employees, the less the employees will experience bullying strain. 
Another purpose of our research was to establish the effects of demographic variables on workplace bullying. In Pakistan, as a result of reforms aimed at including women in the labor force, considerable increase of female faculty members has been observed over the past years. Sadly, bullying in HEI is a much more frequent experience for female faculty members (35\% of which experienced bullying in the workplace), than for male faculty members ( $25 \%$ correspondingly). There are no straightforward explanations of this gender difference. One plausible way of explaining it though is by hinting to socialization differences among men and women. In case of Pakistan, one might argue girls tend to be trained to be less self-assertive, less hostile and more kind as compared to men. Regarding age, our results are similar to results obtained in previous studies [33-35] that found that younger staff experienced more bullying behavior. Accordingly, in our study, we divided the sample into four age groups (26-30, 31-40, 41-50, and 51-60 years). There is a significant difference between these age groups. The findings showed that most of the bullied individuals were under 30 years of age. These findings are in accordance with those of Rayner [36]. Moreover, the workers were classified into two groups: those with less than five years of work experience; and those with more than five years of work experience. In line with the findings of this study, senior employees and those in permanent positions were not victims of bullying as much as less-experienced workers. These findings are consistent with previous results [20-25]; perhaps highly educated employees in senior posts protect themselves from bullying by virtue of their power. It was also hypothesized that unmarried teachers are bullied more than their married colleagues. The findings support our hypothesis. Our findings are consistent with previous findings that showed that marital status is significantly correlated to exposure to workplace bullying and bullying strain [16-18,37]. This may be due to the culture in Pakistani society. In short, from both the findings of our study and the existing literature, there is a strong relationship between an employee's demographic variables and workplace bullying.

Previous studies have revealed that both problem-focused and emotion-focused coping approaches act as a mediator in the relationship between workplace bullying and bullying strain, but no study has presented the best mediation model $[38,39]$. Thus, our study filled this research gap by testing and presenting the best mediation models by using Amos 20.00. The results showed that both problem-focused and emotion-focused coping (see Table 5 and Figure 2) fully mediated the relationship between exposure to bullying and employee strain, thus perhaps emotion-focused coping strategies enhance our ability to overcome strain. Furthermore, employing an emotion-focused coping strategy may help employees to enter into a better state of mind before deploying a problem-focused strategy. In this way, emotion-focused coping helps to manage emotions and to explore solutions, and both types of strategies work better jointly. Our results are aligned, as reported in previous studies $[16,40]$.

\section{Limitations}

The main limitation of this research is that the data were collected by self-reporting, a method that may have caused under-reporting of workplace bullying due to the social taboo. Therefore, it is suggested that future investigations use other methods, for instance focus groups and interviews, in addition to a self-report questionnaire, so that comprehensive information about the frequency, severity, and consequences of bullying can be collected; however, this does not undermine the significance that such large data was collective from a well representative sample for a first time in a systematic manner to achieve certain research objectives which could not be possible in a qualitative research. The study sustains at least some generalizability and its statistics can be used as reference point for Pakistani HEI workplace bullying.

\section{Conclusions}

Although bullying in HEI is a common problem, the issue and its implications have garnered a rather negligible attention in the literature. This paper, by focusing explicitly on the case of Pakistan and its HEI offers an insight into bullying in HEI. The sample used for the purpose of this study is suggestive of the scale and nature of bullying in HEI, not only in Pakistan. Our study confirmed that 
the prevalence of workplace bullying is high in HEI in Pakistan. Bullying has adverse effects on the victim employee and the employing institution [4-7,16-18,41], as well as on the entire economy if employee disengagement, brain-drain and related losses in productivity are accounted for.

The data collected for the purpose of this study and research based on it have substantial empirical value. In other words, this study offers a direct insight into the scale, scope and demographics of bullying in HEI in Pakistan. The findings of this study are also explicit as regards the most efficient strategies aimed at coping with bullying in HEI. This study suggests that both problem-focused and emotion-focused coping strategies should be used simultaneously to address the diverse implications of bullying. Emotion-focused coping strategies help employees to handle the feelings of distress that occur in the result of bullying experience and problem-focused strategies help to find out the solution of bullying problem. So, employees who use coping strategies, not only reduce their strain that occur in the result of bullying but also may reduce exposure to workplace bullying.

This study has the potential of serving as a guide for administrators to develop regulatory frameworks at their respective HEI designed to prevent bullying and mitigate its implications. Clearly, the road from research findings to administrative/regulatory considerations is long. For instance, although, the number of universities in Pakistan increased from 59 in 2002 to 188 in 2017, very little attention has been paid so far to establish policies to address the phenomenon of bulling. We hope that the outcomes of this research will add to the momentum to address the situation where the students' 'best days of their lives' come at the price of our faculty members experiencing the worst days of theirs.

Author Contributions: A.A. conceived the idea, A.A. and A.M. planned the study, performed statistical analysis and drafted the manuscript. A.V. and R.N. edited analysis and critically revised the manuscript. A.M. critically revised the manuscript and supervised the study. F.M. helped drafting the manuscript. All authors contributed significantly to the submitted manuscript. A.M. and R.N. oversaw the project.

Funding: A.M. would like to thank Lahore College for Women University, Pakistan for funding the research reported in this paper through Directorate of research and Post graduate studies. A.V. would like to thank Effat University in Jeddah, Saudi Arabia, for funding the research reported in this paper through the Research and Consultancy Institute.

Conflicts of Interest: The authors declare that there are no conflicts of interest regarding the publication of this paper.

Ethics Statement: The present study was approved by the Ethics Committee of the lead researcher's university. Written, informed consent was obtained from all the participants. However, it was a challenging task to get approval, providing them statistics for the acceptance of this issue as there was no acknowledgment for this phenomenon earlier.

\section{References}

1. Einarsen, S.; Hoel, H.; Notelaers, G. Measuring exposure to bullying and harassment at work: Validity, factor structure and psychometric properties of the negative acts questionnaire-Revised. Work Stress 2009, 23, 23-44. [CrossRef]

2. Meares, M.; Oetzel, J.G.; Derkacs, D.; Ginossar, T. Employee mistreatment and muted voices in the culturally diverse workforce. J. Appl. Commun. Res. 2004, 32, 4-27. [CrossRef]

3. Sheehan, M.; Barker, M.; Rayner, C. Applying strategies for dealing with workplace bullying. Int. J. Manpow. 1999, 20, 50-56. [CrossRef]

4. Lutgen-Sandvik, P. Take This Job and ... : Quitting and Other Forms of Resistance to Workplace Bullying. Commun. Monogr. 2006, 73, 406-433. [CrossRef]

5. Saunders, P.; Huynh, A.; Goodman-Delahunty, J. Defining workplace bullying behaviour professional lay definitions of workplace bullying. Int. J. Law Psychiatry 2007, 30, 340-354. [CrossRef] [PubMed]

6. Al-Karim, S.; Parbudyal, S. 20 Years of workplace bullying research: A review of the antecedents and consequences of bullying in the workplace. Aggress. Violent Behav. 2012, 17, 581-589. [CrossRef]

7. Branch, S.; Murray, J. Workplace bullying: Is lack of understanding the reason for inaction? Organ. Dyn. 2015, 44, 287-295. [CrossRef] 
8. Visvizi, A.; Lytras, M.D.; Daniela, L. The Future of Innovation and Technology in Education: A Case for Restoring the Role of the Teacher as a Mentor. In The Future of Innovation and Technology in Education: Policies and Practices for Teaching and Learning Excellence; Visvizi, A., Lytras, M.D., Daniela, L., Eds.; Emerald Publishing: Bingley, UK, 2018; pp. 1-10. ISBN 9781787565562. [CrossRef]

9. Daniela, L.; Visvizi, A.; Gutiérrez-Braojos, C.; Lytras, M.D. Sustainable Higher Education and TechnologyEnhanced Learning (TEL). Sustainability 2018, 10, 3883. [CrossRef]

10. Fox, S.; Stallworth, L.E. The battered apple: An application of stressor-emotion control/support theory to teachers' experience of violence and bullying. Hum. Relat. 2010, 63, 927-954. [CrossRef]

11. Einarsen, S. The nature and causes of bullying at work. Int. J. Manpow. 1999, 20, 16-27. [CrossRef]

12. Ahmad, S. From Brain Drain to Brain Gain. 6 May 2018. Available online: https://dailytimes.com.pk/236471/ from-brain-drain-to-brain-gain/ (accessed on 7 March 2019).

13. Shadman, A. Pakistan's Higher Education in Crisis. 1 August 2017. Available online: https://propakistani.pk/ 2017/08/01/pakistans-higher-education-crisis-govt-shifts-funds-transport-schemes/ (accessed on 7 March 2019).

14. Keelan, E. Bully for you. Accountancy 2000, 125, 56.

15. Namie, G.; Namie, R. The Bully at Work: What You Can Do to Stop the Hurt and Reclaim Your Dignity on the Job; Sourcebooks: Naperville, IL, USA, 2009.

16. Keashly, L.; Neuman, J.H. Faculty Experiences with Bullying in Higher Education. Adm. Theory Prax. 2010, 32, 48-70. [CrossRef]

17. Misawa, M.; Rowland, M.L. Academic Bullying and Incivility in Adult, Higher, Continuing, and Professional Education. Adult Learn. 2015, 26, 3-5. [CrossRef]

18. Zabrodska, K.; Kveton, P. Prevalence and Forms of Workplace Bullying Among University Employees. Empl. Responsib. Rights J. 2013, 25, 89. [CrossRef]

19. Carver, C.S.; Connor-Smith, J. Personality and coping. Annu. Rev. Psychol. 2010, 61, 679-704. [CrossRef]

20. Carver, C.S. You want to measure coping but your protocol's too long: Consider the brief cope. Int. J. Behav. Med. 1997, 4, 92-100. [CrossRef]

21. Imran, N.; Jawaid, M.; Haider, I.I.; Masood, Z. Bullying of junior doctors in Pakistan: A cross-sectional survey. Singap. Med. J. 2010, 51, 592-595.

22. Zapf, D.; Gross, C. Conflict escalation and coping with workplace bullying: A replication and extension. Eur. J. Work Organ. Psychol. 2001, 10, 497-522. [CrossRef]

23. Anjum, A.; Shoukat, A. Workplace bullying: Prevalence and risk groups in a Pakistani sample. J. Public Adm. Gov. 2013, 3, 92-97. [CrossRef]

24. Carver, C.S.; Scheier, M.F.; Weintraub, J.K. Assessing coping strategies: A theoretically based approach. J. Personal. Soc. Psychol. 1989, 56, 267-283. [CrossRef]

25. Anjum, A.; Muazzam, A. An Assessment of Workplace Bullying in Educational Institutes of Lahore, Pakistan. Unpublished Doctoral Thesis, Lahore College for Women University, Punjab, Pakistan, 2018.

26. Baron, R.M.; Kenny, D.A. The moderator-mediator variable distinction in social psychological research: Conceptual, strategic and statistical considerations. J. Personal. Soc. Psychol. 1986, 51, 1173-1182. [CrossRef]

27. Bentler, P.M. Comparative fit indexes in structural models. Psychol. Bull. 1990, 107, 238-246. [CrossRef]

28. Cohen, J. A power primer. Psychol Bull. 1992, 112, 155-159. [CrossRef]

29. Arbuckle, J.L. IBM ${ }^{\circledR}$ SPSS ${ }^{\circledR}$ Amos ${ }^{\mathrm{TM}} 21$ User's Guide; Amos Development Corporation, IBM Corp: Armonk, NY, USA, 2012.

30. Hayes, A.F. Introduction to Mediation, Moderation, and Conditional Process Analysis: A Regression-Based Approach; Guilford Press: New York, NY, USA, 2013.

31. Mikkelsen, E.G.; Einarsen, S. Basic assumptions and post-traumatic stress among victims of workplace bullying. Eur. J. Work Organ. Psychol. 2002, 11, 87-111. [CrossRef]

32. Lewis, D. Workplace bullying-Interim findings of a study in further and higher education in wales. Int. J. Manpow. 1999, 20, 106-118. [CrossRef]

33. Mckay, R.; Arnold, D.; Fratzl, J.; Thomas, R. Workplace bullying in academia: A Canadian study. Empl. Responsib. Rights J. 2008, 20, 77-100. [CrossRef]

34. Simpson, R.; Cohen, C. Dangerous work: The gendered nature of bullying in the context of higher education. Gend. Work Organ. 2004, 11, 163-186. [CrossRef]

35. Hubert, A.B.; Veldhoven, M.V. Risk sectors for undesirable behavior and mobbing. Eur. J. Work Organ. Psychol. 2001, 10, 415-424. [CrossRef] 
36. Rayner, C. From research to implementation: Finding leverage for prevention. Int. J. Manpow. 1999, 20, 28-38. [CrossRef]

37. Keashly, L. Emotional abuse in the workplace: Conceptual and empirical issues. J. Emot. Abus. 1998, 1, 85-117. [CrossRef]

38. Olafsson, R.F.; Johannsdottir, H.L. Coping with bullying in the workplace: The effect of gender, age and type of bullying. Br. J. Guid. Couns. 2004, 32, 319-333.

39. Moreno-Jimenez, B.; Rodriguez-Munoz, A.; Salin, D.; Benadero, M. Workplace bullying in southern Europe: Prevalence, forms and risk groups in a Spanish sample. Int. J. Organ. Behav. 2008, 13, 95-109.

40. Deniz, N.; Ertosun, N.D. The relationship between personality and being exposed to workplace bullying or mobbing. J. Glob. Strateg. Manag. 2010, 7, 129-142. [CrossRef]

41. D'Cruz, P.; Noronha, E. Protecting my interests: HRM and targets' coping with workplace bullying. Qual. Rep. 2010, 15, 507-534.

(C) 2019 by the authors. Licensee MDPI, Basel, Switzerland. This article is an open access article distributed under the terms and conditions of the Creative Commons Attribution (CC BY) license (http://creativecommons.org/licenses/by/4.0/). 